\title{
Can we have a rationalized selection of intra-aortic balloon pump, Impella, and extracorporeal membrane oxygenation in the catheterization laboratory?
}

\author{
Giulio Russo ${ }^{1,2,3}$ (D) Francesco Burzotta ${ }^{1,2}$, Cristina Aurigemma ${ }^{1}$, \\ Daniela Pedicino ${ }^{1,2}$, Enrico Romagnoli ${ }^{1}$, Carlo Trani ${ }^{1,2}$ \\ ${ }^{1}$ Fondazione Policlinico Universitario A Gemelli IRCSS, Rome, Italy \\ ${ }^{2}$ Università Cattolica del Sacro Cuore, Rome, Italy \\ ${ }^{3}$ University Heart Center, University Hospital, Zurich, Switzerland
}

\begin{abstract}
Cardiac assistance represents an emerging issue in cardiovascular medicine. The evolution of invasive cardiology techniques is making the catheterization laboratory one of the main hospital sites where implantation of percutaneous ventricular assistance devices (PVADs) is discussed and performed. Among available PVADs, intra-aortic balloon pump (IABP), Impella, and extracorporeal membrane oxygenation (ECMO) are the most popular and offer completely different levels and ways to assist critical patients. The main settings calling for PVAD consideration in the catheterization laboratory are clinically indicated high-risk patients (CHIP) undergoing percutaneous coronary intervention (PCI) and patients with cardiogenic shock or refractory cardiac arrest.

In CHIP, PVAD serves the purpose of preventing hemodynamic collapse during PCI. This may also allow more extensive revascularizations and higher quality revascularization plans (imaging use, debulking, stent result optimization). IABP or Impella are more commonly selected whereas ECMO is seldom considered as a third option for highly selected patients. The "elective" nature of CHIP-PCI should allow careful procedure planning (peripheral artery disease assessment, access site selection and management) in order to minimize vascular/bleeding complications.

Cardiogenic shock is still associated with high mortality rates, and PVAD theoretically offers further recovery chances. The lack of benefit observed with systematic IABP use is currently prompting consideration of the roles of Impella and ECMO. Prolonged assistance is often needed. Thus, team decisions and shared protocols for PVAD selection have to be promoted, taking into consideration available resources and operators' skills.

In this paper, we critically review the available data in the field and highlight the possible decisionmaking hubs that catheterization-laboratory teams may consider in order to rationalize PVAD selection. (Cardiol J 2022; 29, 1: 115-132)

Key words: extracorporeal membrane oxygenation, Impella, intra-aortic balloon pump, percutaneous ventricular assist device, personalized medicine
\end{abstract}

Address for correspondence: Francesco Burzotta, MD, PhD, Institute of Cardiology, Fondazione Policlinico Universitario A. Gemelli IRCCS, Università Cattolica del Sacro Cuore, L.go A. Gemelli 1, 00168 Rome, Italy, tel: +39-06-30154187, fax: +39-06-3055535, e-mail: francescoburzotta@gmail.com

Received: 24.10.2020 Accepted: 24.11.2020 Early publication date: 17.12 .2020

This manuscript has been realized during the PhD program.

This article is available in open access under Creative Common Attribution-Non-Commercial-No Derivatives 4.0 International (CC BY-NC-ND 4.0) license, allowing to download articles and share them with others as long as they credit the authors and the publisher, but without permission to change them in any way or use them commercially. 


\section{Introduction}

The management of critically ill cardiac patients has aroused great interest in recent years. Percutaneous coronary intervention (PCI) techniques have expanded and gained respect as a valuable alternative to cardiac surgery in patients with complex coronary anatomy and high surgical risk. Given an aging population and improved treatments for chronic conditions and comorbidities, the high-risk PCI population, presenting with both stable and unstable conditions, is expanding in the catheterization laboratories. In parallel, the recognized benefit of coronary angiography and urgent myocardial revascularization in patients with critical clinical conditions like cardiogenic shock or refractory cardiac arrest put access to a catheterization laboratory in the pipeline of contemporary managing algorithms. This has raised interest in the search for the best management of patients with critical hemodynamic conditions.

The two conditions of PCI in clinically indicated high-risk patients (CHIP) and cardiogenic shock (CS) or refractory cardiac arrest, despite their completely different nature, share the characteristics of raising discussion about the possibility to benefit from hemodynamic support devices. For instance, this issue is particularly burning in the catheterization laboratory because such patient subsets systematically receive diagnostic and interventional procedures during which hemodynamic deterioration may occur [1]. Among the available percutaneous ventricular assist device (PVAD) systems, three are widely used: intra-aortic balloon pump (IABP), Impella (Abiomed Inc., Danvers, MA), and extracorporeal membrane oxygenation (ECMO). A fourth PVAD, the TandemHeart, is limited by the need for trans-septal puncture and is routinely used only in a limited number of highly experienced centers. Accordingly, its adoption represents an option only in selected environments.

In this paper, we critically review the available data in the field and highlight, within the lack of strong clinical evidence, the possible decisionmaking hubs that are encountered when selecting IABP, Impella, and ECMO in both CHIP and CS.

\section{High-risk PCI: Definition and hemodynamics}

Currently, no univocal definition of high-risk $\mathrm{PCI}$ exists, and it represents a continuously evolving concept. The risk scores (EuroSCORE and
Society of Thoracic Surgery [STS] score) were derived from studies in the surgical field, and such scores are currently used to detect patients at higher risk for surgical interventions [2]. At the same time, the high surgical risk also predicts complexity in the case of PCI. Not surprisingly, the surgical scores may also be used to provide a mortality stratification for patients undergoing PCI (with event rates being generally lower than with surgery) $[3,4]$.

In the field of high-risk PCI, procedural planning and technical issues need to be carefully assessed $[5,6]$ when dealing with patients with impaired left ventricular (LV) function. First, coronary flow blockage may impair hemodynamic stability throughout the procedure when the underlined territory is large and LV function is poor. Highly calcified lesions, bifurcations, chronic total occlusion, and multivessel disease may require multiple balloon dilatations, increasing the risk for prolonged myocardial ischemia and consequent hemodynamic collapse. Similar consequences may come from vessel dissections, distal embolization, and sidebranch occlusion. As regards multivessel coronary artery disease, it has been demonstrated that an extensive revascularization $[2,7]$ may impact longterm prognosis and that Impella may offer strong and reliable LV support allowing more complex revascularization procedures as compared to IABP in patients without acute myocardial infarction (MI) [8]. Alongside this, the myocardium at risk as measured by British Cardiovascular Intervention Society (BCIS) Myocardial Jeopardy Score [9] can be included in the pre-procedural risk assessment [10] both to predict the risk of hemodynamic collapse [11] and to assess the final revascularization extent through the BCIS Revascularization Index [10]. As regards LV function, no definite cut-off exists to indicate the need for any PVAD. However, reduced LV function increases the likelihood of hemodynamic instability during complex PCI procedures [12]. Finally, LV end-diastolic pressure represents an easy-to-obtain invasive measure of cardiac compensation and has been demonstrated to significantly stratify mortality in invasively managed acute coronary syndromes [13]. In this regard, an accurate evaluation of diastolic function in the preprocedural setting might be of pivotal importance for risk stratification, alongside LV systolic function (Table 1).

In such a scenario, LV support may reduce LV filling pressures and prevent critical cardiac output decrease. Such "LV unloading" is recognized to 
Table 1. Echocardiographic features to consider in percutaneous ventricular assist device (PVAD) decision-making.

\begin{tabular}{|c|c|c|}
\hline & Value & Notes \\
\hline \multicolumn{3}{|l|}{ Systolic LV function } \\
\hline \multirow[t]{2}{*}{ LV ejection fraction } & $<35 \%$ & \\
\hline & $\begin{array}{l}>35 \% \text { with large amount of } \\
\text { myocardium at risk (Jeopardy } \\
\text { score) }\end{array}$ & $\begin{array}{l}\text { Consider PVAD also for normal ejection fraction with } \\
\text { indirect signs of reduced cardiac output (low LVOT } \\
\text { VTI) or other signs of LV dysfunction (i.e. global } \\
\text { longitudinal strain indicating severe longitudinal } \\
\text { dysfunction) }\end{array}$ \\
\hline LVOT VTI & $<15 \mathrm{~cm}$ & \\
\hline \multicolumn{3}{|l|}{ Diastolic LV function } \\
\hline \multirow[t]{2}{*}{ E/A ratio } & $\begin{array}{l}\text { E<A velocity: abnormal diastolic } \\
\text { function }\end{array}$ & \multirow{2}{*}{$\begin{array}{l}\text { For E/E' values between } 10 \text { and } 15 \text { add other param- } \\
\text { eters (pulmonary vein PW Doppler, color M-mode } \\
\text { propagation velocity, B-lines at lung ultrasound) } \\
\text { Pre-procedural assessment of LV filling pressure } \\
\text { allows to: 1) choose among different PVADs; } \\
\text { 2) consider LV venting strategies for VA-ECMO; } \\
\text { 3) adequately plan weaning strategies }\end{array}$} \\
\hline & E $>A$ velocity: restrictive physiology & \\
\hline$E / E^{\prime}$ ratio & $\begin{array}{l}\geq 15 \text { (septal or average) indicates } \\
\text { elevated LAP }\end{array}$ & \\
\hline \multirow[t]{2}{*}{ E deceleration time } & $>240$ ms: abnormal diastolic function & \\
\hline & $<160$ ms: restrictive physiology & \\
\hline \multirow[t]{2}{*}{ IVRT } & $>110 \mathrm{~ms}$ : abnormal diastolic function & \\
\hline & $<60 \mathrm{~ms}$ : restrictive physiology & \\
\hline \multicolumn{3}{|l|}{ RV function } \\
\hline TAPSE & $<15 \mathrm{~mm}$ & $\begin{array}{l}\text { In case of reduced RV function, consider biventricular } \\
\text { systems (ECMO, Bipella) }\end{array}$ \\
\hline S wave TDI & $<9 \mathrm{~cm} / \mathrm{s}$ & \\
\hline $\begin{array}{l}\text { Fractional area } \\
\text { change }\end{array}$ & $<35 \%$ & \\
\hline \multicolumn{3}{|c|}{ Valvular heart disease } \\
\hline Mitral/aortic & $\begin{array}{l}\text { Assess and quantify regurgitation } \\
\text { or stenosis }\end{array}$ & Check for contraindications \\
\hline LV thrombus & $\begin{array}{l}\text { Look for intraventricular thrombus } \\
\text { if Impella is planned }\end{array}$ & \\
\hline
\end{tabular}

LAP — left atrial pressure; LV — left ventricle; LVOT — left ventricle outflow tract; VTI — velocity time integral; IVRT — isovolumic relaxation time; RV - right ventricle; TAPSE — tricuspid annular plane systolic excursion; TDI - tissue Doppler imaging; VA-ECMO - veno-arterial extracorporeal membrane oxygenation

limit infarct size in experimental canine models $[14,15]$ and to avoid hemodynamic collapse when multiple angioplasty-balloon inflations are needed [16].

On the basis of this evidence, PVAD might be considered a valuable approach to move from the concept of PCI performed accepting high risk ("high-risk PCI") to that of PCI performed with the help of devices that may reduce hemodynamicintolerance risk ("protected-PCI") [6].

\section{PVADs and high-risk PCI}

\section{Intra-aortic balloon pump}

The IABP represents the traditional method for mechanical circulatory support and was first used by Kantrowitz et al. [17] in 1968 for the management of acute MI complicated by CS. It works by deflating during systole (QRS-T segment) and inflating during diastole (T-P segment). In this way diastolic augmentation during inflation contributes 
to coronary, cerebral, and systemic circulation. Diastolic pressure augmentation during balloon inflation is influenced by Weber and Janicki [18]:

- balloon position: the closer the IABP is positioned to the aortic valve, the greater the diastolic pressure elevation;

- balloon volume: when the balloon volume equalizes the stroke volume, then the diastolic augmentation is maximized;

- balloon diameter and occlusivity: the greatest augmentation occurs with complete aortic occlusion. The size of the aorta is related to the patient size, age, and weight. Usually, balloon dimensions are based on patient height. Different balloon volumes from $25 \mathrm{cc}$ to $50 \mathrm{cc}$ are available on the market, with $40 \mathrm{cc}$ being the most commonly used;

- balloon configuration/timing;

- stroke volume: diastolic augmentation is maximized when stroke volume is equal to balloon volume. If stroke volume is very low (e.g. $25-30 \mathrm{~mL})$ or very high $(95-100 \mathrm{~mL})$, augmentation will be limited;

- arterial pressure and heart rate.

There are several cardiovascular effects induced by IABP: it reduces the end-diastolic aortic pressure by up $30 \%$, indicating systolic unloading; it decreases the LV wall tension; and it decreases the rate of $L V$ pressure rise $(\mathrm{dp} / \mathrm{dt})$. There is controversial evidence on the degree of post-stenotic coronary blood flow augmentation achieved despite the increase in perfusion pressure. Some reports demonstrate no increase in coronary blood flow distal to critical stenosis [19,20], whereas others demonstrated an increase of distal flow independent of any stenosis [21, 22].

The final effect of IABP is to lower the LV afterload, and to decrease myocardial oxygen demand (reducing systolic wall tension and increasing coronary perfusion pressure), thus improving the myocardial supply/demand balance. Finally, cardiac output increases because of the improved myocardial contractility as a result of the reduced afterload and of the possible increased coronary blood flow [23]. Currently, several IABP models produced by different manufacturers are available. Catheter size varies from 8 to $9 \mathrm{Fr}$, and some of them are provided with fiber-optic pressure sensing.

\section{IABP and high-risk PCI}

According to the current European guidelines, the role of IABP in the setting of high-risk PCI is still debated and unclear [24-26], whereas Ameri- can Heart Association/American College of Cardiology (AHA/ACC) guidelines suggest that elective insertion of an appropriate hemodynamic support device, as an adjunct to PCI, may be reasonable in carefully selected high-risk patients (Class IIb, LoE: C) [27], although no support device is specified and selection criteria for high-risk patients are not defined (Table 2)

Past clinical experience supports the usefulness of elective IABP for high-risk PCI [28-30]. However, data from the National Cardiovascular Data Registry (NCDR) found no difference in overall mortality with use of the IABP for high-risk PCI. The registry enrolled almost 19,000 "high-risk" patients treated with IABP-supported PCI [31]. Of note, alongside patients with unprotected left main artery as the target vessel or with ST elevation, the study population included also those with CS. Routine prophylactic use of IABP in high-risk PCI has definitely come into question following the results of a large randomized trial [32]. A total of $301 \mathrm{pa}-$ tients undergoing high-risk PCI, defined as severe $\mathrm{LV}$ systolic dysfunction (left ventricular ejection fraction $[\mathrm{LVEF}]<30 \%$ ) and extensive coronary artery disease, were randomized in the BCIS- 1 trial to either "planned" IABP or "no planned" IABP prior to PCI. No difference was reported in the primary endpoint of major adverse cardiac and cerebrovascular events at 28 days, despite a marked reduction in procedural complications. In addition, bleeding and access-site complications trended higher with routine IABP use. Mortality was not different at 6 months but was significantly reduced at long-term follow-up (median of 51 months), with a relative reduction of $34 \%$ of all-cause death in the "planned" IABP group [33]. Because the trial was not powered to reveal a mortality difference, these results can only be deemed hypothesis generating. However, they suggest the importance of a proper procedure planning in such critical patients or, given the rate of bailout IABP, an initial strategy of standby IABP for PCI in those patients with compromised myocardial reserve, and extensive coronary artery disease would therefore seem a reasonable strategy.

Independently of the scientific data, low costs, wide availability, ease of use, and low invasiveness make IABP an important tool in PCI clinical practice. Accordingly, IABP can be considered a valuable option in all situations requiring a lowto-moderate grade of LV support (Fig. 1).

Of note, because anytime cardiac assistance is not electively used, it should be promptly inserted on bail-out; when high-suspicion of 
Table 2. Use of percutaneous ventricular assist device (PVAD) in high-risk percutaneous coronary intervention (PCI) according to international guidelines.

\begin{tabular}{|c|c|c|c|c|c|}
\hline PVAD & $\begin{array}{l}\text { Clinical } \\
\text { setting }\end{array}$ & Guidelines & $\begin{array}{c}\text { Recommendation } \\
\text { class }\end{array}$ & $\begin{array}{l}\text { Level of } \\
\text { evidence }\end{array}$ & Recommendation \\
\hline \multirow[t]{2}{*}{$\begin{array}{l}\text { MECHANICAL } \\
\text { SUPPORT }\end{array}$} & $\begin{array}{l}\text { ST-segment } \\
\text { elevation } \\
\text { myocardial } \\
\text { infarction }\end{array}$ & $\begin{array}{c}\text { STEMI ESC } \\
2017\end{array}$ & & & $\begin{array}{c}\text { Mechanical circulatory support } \\
\text { may be considered as a rescue } \\
\text { therapy in order to stabilize the } \\
\text { patients and preserve organ } \\
\text { perfusion (oxygenation) as } \\
\text { a bridge to recovery of myocardial } \\
\text { function, cardiac transplantation, } \\
\text { or even left ventricle assist device } \\
\text { destination therapy on an } \\
\text { individual basis }\end{array}$ \\
\hline & $\begin{array}{l}\text { High-risk } \\
\text { patients* }\end{array}$ & $\begin{array}{l}\mathrm{PCl} \text { ACCF/ } \\
\text { /AHA/SCAI } \\
2011\end{array}$ & Ilb & $\mathrm{C}$ & $\begin{array}{l}\text { Elective insertion of an appropriate } \\
\text { hemodynamic support device as an } \\
\text { adjunct to PCI may be reasonable in } \\
\text { carefully selected high-risk patients }\end{array}$ \\
\hline
\end{tabular}

* "High-risk patients may include those undergoing unprotected left main or last-remaining-conduit PCl, those with severely depressed ejection fraction undergoing $\mathrm{PCl}$ of a vessel supplying a large territory, and/or those with cardiogenic shock. Patient risk, hemodynamic support, ease of application/removal, and operator and laboratory expertise are all factors involved in consideration of use of these devices".

Classes of recommendations:

I: Evidence and/or general agreement that a given treatment or procedure is beneficial, useful, effective

Ila: Weight of evidence/opinion is in favor of usefulness/efficacy

Ilb: Usefulness/efficacy is less well established by evidence/opinion

III: Evidence or general agreement that the given treatment or procedure is not useful/effective, and in some cases may be harmful

Level of evidence:

A: data derived from multiple randomized clinical trials or meta-analyses

$B$ : data derived from single randomized clinical trial or large non-randomized studies

C: consensus of opinion of the experts and/or small studies, retrospective studies, registries

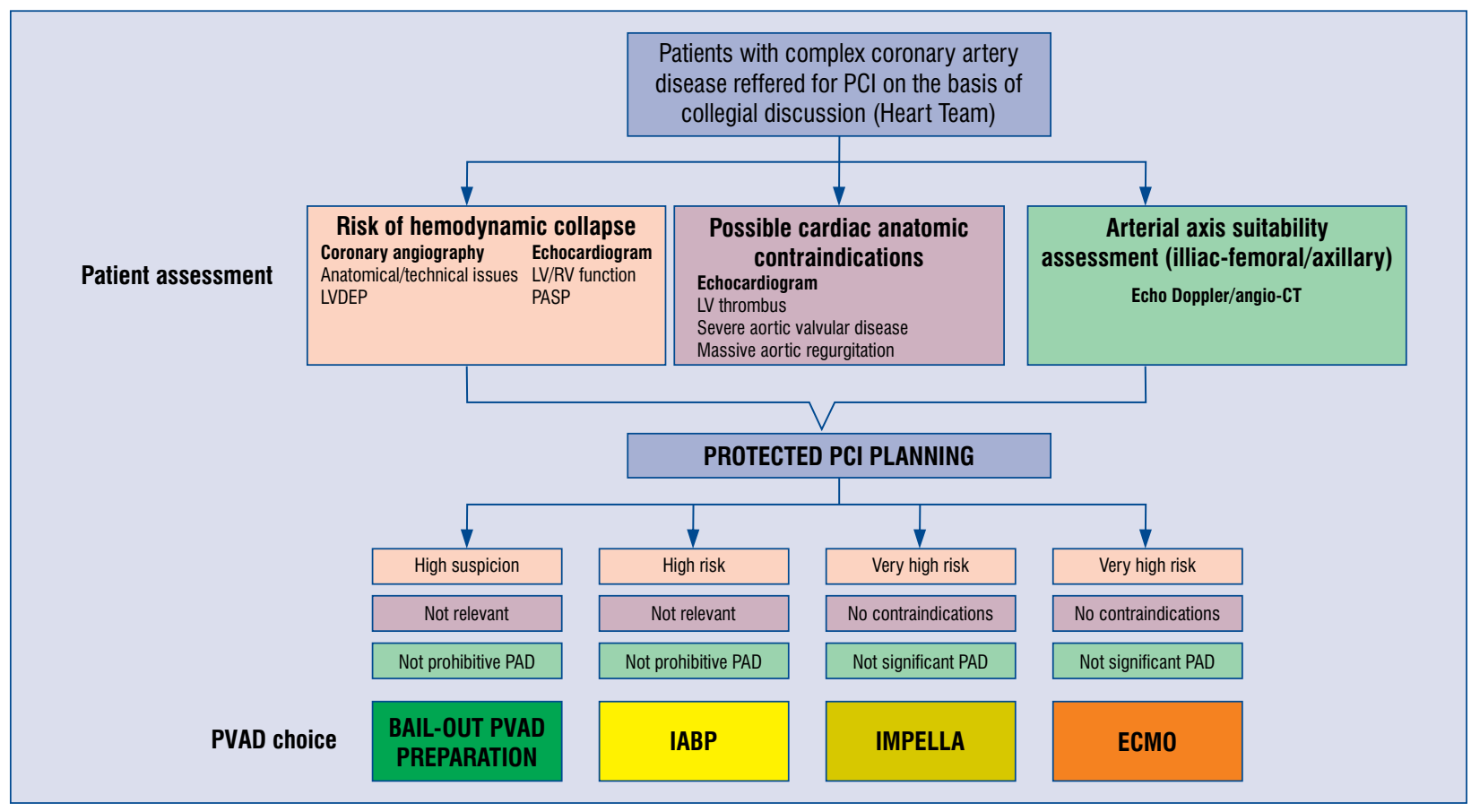

Figure 1. Proposed pre-procedural assessment and percutaneous ventricular assistance device (PVAD) choice in the context of high-risk percutaneous coronary intervention (PCI); LVEDP - left ventricle end-diastolic pressure; PASP — pulmonary artery systolic pressure; PAD — peripheral artery disease; CT — computed tomography; IABP — intraaortic-balloon pump; LV — left ventricle; RV — right ventricle; ECMO - extracorporeal membrane oxygention. 
hemodynamic collapse exists, a safe approach would be to prepare for PVAD insertion. To do this, the femoral access can be effectively gained and a small-bore sheath (e.g. $5 \mathrm{Fr}$ ) inserted to facilitate easy and fast exchange if needed. Alongside access site preparation, the device and the team involved (e.g. operators, technicians, nurses) should be prepared for bail-out PVAD placement as well (Fig. 1).

\section{Percutaneous LV-to-aorta circulatory support: Impella}

The Impella (Impella, Abiomed Inc., Danvers, MA) is a microaxial pump delivering blood from the $\mathrm{LV}$ forward into the ascending aorta. It is inserted through the femoral route (13-14 Fr) or it can be placed surgically through the axillary artery. Once the access site has been achieved [34], it is advanced from the aorta into the LV. Because it requires aortic valve crossing, moderate-tosevere aortic valve disease is a contraindication for its use. It is connected to an "Automated Impella Controller", which provides a step-by-step guide to the device implantation and controls the Impella catheter performance, monitors for alarms, and displays real-time hemodynamic and catheter position information. The latest updates have implemented the "Smart Assist Platform", providing useful information about the position of the Impella, to facilitate its repositioning in intensive care units without the need for imaging, and about hemodynamic features (LV enddiastolic pressure, mean arterial pressure, and cardiac power output).

According to the manufacturers' instructions for authors, the device is intended for short-term use (up to 4 days in the case of cardiogenic shock), although the new "PROPELLA" concept in the context of myocarditis has increased the time of support [35]. The device output may vary from 2.5 to $5.0 \mathrm{~L} / \mathrm{min}$, according to the different pumps. The main Impella pump characteristics have been summarized elsewhere [33].

The Impella increases the mean arterial pressure, cardiac output, and systemic and coronary perfusion. Its main effect is a significant LV unloading, resulting in filling pressure decrease and afterload. The direct unloading of LV and the coronary blood flow increase lead to significant oxygen supply improvement and reduction of myocardial oxygen consumption, with cardio protective effects. The final native stroke volume can be reduced, although the device replaces the pump function.

\section{Impella and high-risk PCI}

The introduction of the Impella support device has brought a significant change in the field of highrisk PCI, allowing highly complex procedures for patients deemed not suitable for surgery and at high risk for intraprocedural hemodynamic collapse (Table 2) [36].

Most of the data about the use of the Impella in the context of high-risk PCI come from the PROTECT II trial [8]. A total of 448 patients were randomized to IABP or Impella 2.5 for elective high-risk PCI. Inclusion criteria were similar to those of BCIS-1 although the primary end-point was made of a composite of heterogeneous adverse events, and patients with ST segment elevation myocardial infarction (STEMI) within 24 hours or not normalized myocardial enzymes were excluded from the study. Of note, the trial was interrupted due to futility in the prespecified endpoints. At 90-day follow-up the major adverse cardiac event occurrence was significantly lower in the Impella group as compared to the IABP group $(\mathrm{p}=0.023$ in the "per protocol" analysis, $\mathrm{p}=0.066$ in the "intention-to-treat" analysis). Moreover, the different use of adjunctive devices (e.g. Rotablator) and the higher complexity of the Impella-group patients suggests different PCI planning and management between the two groups. Finally, the overall duration of support was significantly lower in the Impella group, with only $6 \%$ of patients being discharged from the cath lab on Impella, as compared to $37 \%$ of patients keeping the IABP after the end of the procedure.

Alongside this, the two largest published series, the multicenter Europella and USpella registries, provided new data regarding the real-world practice [37, 38]. The baseline characteristics of the 144 patients in the Europella Registry suggest that these patients were indeed at high risk: almost two third had an LVEF less than 40\%, 39\% had more than three target lesions, 53\% underwent left main coronary artery PCI, and $17 \%$ had intervention on a last remaining patent vessel. The logistic EuroScore was $15 \pm 12.2$, which further indicated the high-risk nature of this population. Despite this, overall mortality was only $5.5 \%$ at 30 days. The multicenter USpella Registry included results on 178 high-risk patients undergoing Impellasupported PCI. Similarly to the Europella, $62 \%$ had an LVEF less than $30 \%$ before intervention. Results showed an $8 \%$ rate of 30 -day major adverse cardiac events, while survival was $96 \%$ at 30 days, $91 \%$ at 6 months, and $88 \%$ at 1 year. In addition, only $30 \%$ of patients remained in New York Heart 
Association (NYHA) class III or IV heart failure, consistent with an absolute increase in mean ejection fraction from $31 \%$ to $37 \%$. This latter improvement resulted in a $29 \%$ reduction in the anticipated need for implantable cardioverter defibrillators because the percentage of patients with an ejection fraction less than $30 \%$ was reduced from $62 \%$ to $44 \%$ [15].

These data were consistent with those coming from a recent large Italian registry [10]. It included 86 patients undergoing high-risk PCI with Impella support. After 14 months of follow-up the all-cause death was $10 \%$. Of note, at follow-up a $205 \%$ increase in patients with LVEF $>35 \%$ was observed with BCIS Jeopardy Score Revascularization Index, significantly affecting long-term survival. Based on the current available data, the Impella should be considered in cases where the risk of hemodynamic collapse is very high and when no device contraindications are met (Fig. 1).

\section{Percutaneous ECMO}

ECMO has been increasingly used over the past decade to support patients with cardiopulmonary collapse [1]. Veno-arterial extracorporeal membrane oxygenation (VA-ECMO) provides cardiopulmonary support for patients in profound CS as a bridge to the following:

- myocardial recovery;

- durable mechanical circulatory support;

- heart transplant.

In a VA-ECMO circuit, deoxygenated blood is pulled from the venous circulation by a pump via a large-bore cannula (21-23 Fr) inserted through the femoral vein. Blood passes through the pump into an oxygenator where gas exchange occurs. Finally, oxygenated blood returns via another largebore cannula (15-17 Fr) to the arterial circulation, usually inserted into the common femoral artery.

In order to reduce the risk of critical limb ischemia in the cannulated femoral artery, distal perfusion catheters/sheath introducers, which direct a proportion of the returned oxygenated blood flow from the ECMO circuit to the distal limb, are positioned [39]. In this way it provides continuous, non-pulsatile output $(>4.5 \mathrm{~L} / \mathrm{min})$ and adequate blood oxygenation. ECMO is also known to determine a significant increase in LV pre- and afterload and in myocardial oxygen consumption that may limit its cardio protective effect [21].

During ECMO support, vasodilators might reduce afterload and LV end-diastolic pressure, while inotropes can increase contractility. In order to achieve LV unloading IABP [40], an Impella [41], a surgical LV vent, or a percutaneous balloon atrioseptostomy [42] might be added as adjunctive devices.

Due to huge cannula sizes, the implantation procedure requires considerable technical skill, and vascular/bleeding complications are common. Recent experience has started to highlight percutaneous implantation techniques as a promising way to increase ECMO safety. In particular, a recent propensity-matched analysis compared percutaneous versus surgical VA-ECMO showed significantly higher survival in the percutaneous groups and lower cannulation site infection. However, a significantly higher rate of vascular complications after cannula removal was reported, mainly represented by persistent bleeding requiring surgical repair [43].

\section{ECMO and high-risk PCI}

ECMO experience for high-risk PCI is limited to a few monocentric observational studies or individual case reports $[44,45]$. They all demonstrate feasibility and efficacy of ECMO, although vascular complications and bleedings may represent a major concern. A recent case series included 5 patients undergoing elective high-risk PCI with ECMO support [46]. The mean LVEF was $26.6 \pm 18.0 \%$. Most procedures were unprotected left main PCIs, and there was only one chronic total occlusion through the last remaining conduit. All PCIs were successful, and ECMO was successfully weaned in all cases, with the duration of support being $<24$ hours in 4 cases. There was no occurrence of in-hospital and 1-year major adverse events. However, 1 patient required femoral artery surgical repair, and 2 patients required general anesthesia. The limited experience and the ECMO invasiveness call for very selective use in the setting of high-risk PCI when the need for assistance is felt to be mandatory, anatomic contraindications for Impella (or its unavailability) are present, and vascular axes are suitable for insertion (Fig. 1).

\section{Cardiogenic shock}

Currently, no univocal definition exists, and there are slight differences among the current European guidelines and the recent trials (Table 3) [47-50]. The recent Heart Failure Association position statement defined CS as a syndrome caused by primary cardiovascular disorder in which inadequate cardiac output results in a lifethreatening state of tissue hypoperfusion associated with impairment of tissue oxygen metabolism and hyperlactatemia, which, depending on its 
Table 3. Cardiogenic shock definitions according to European guidelines and recent clinical trials.

\begin{tabular}{|c|c|c|}
\hline ESC Guidelines [47] & IABP SHOCK II [48] & SHOCK TRIAL [49] \\
\hline \multirow[t]{2}{*}{$\begin{array}{l}\mathrm{SBP} \leq 90 \mathrm{mmHg} \text { with adequate } \\
\text { blood volume and clinical or labora- } \\
\text { tory signs of hypoperfusion }\end{array}$} & $\begin{array}{c}\mathrm{SBP} \leq 90 \mathrm{mmHg} \text { for at least } 30 \mathrm{~min} \\
\text { or need for catecholamine in order } \\
\text { to achieve } \mathrm{SBP} \geq 90 \mathrm{mmHg}\end{array}$ & $\begin{array}{c}\mathrm{SBP} \leq 90 \mathrm{mmHg} \text { for at least } 30 \mathrm{~min} \\
\text { or need for support in order to } \\
\text { achieve SBP } \geq 90 \mathrm{mmHg}\end{array}$ \\
\hline & + & + \\
\hline Hypoperfusion: clinical signs & Pulmonary congestion signs & Hypoperfusion signs: \\
\hline Cold extremities & & Cold skin \\
\hline Oliguria & & Diuresis $<30 \mathrm{~mL} / \mathrm{h}$ \\
\hline \multicolumn{3}{|l|}{ Mental confusion } \\
\hline \multicolumn{3}{|l|}{ Dizziness } \\
\hline & + & + \\
\hline Hypoperfusion: lab signs & Hypoperfusion signs: & Hemodynamic criteria \\
\hline Metabolic acidosis & Altered mental status & $\mathrm{Cl} \leq 2.2 \mathrm{~L} / \mathrm{min} / \mathrm{m}$ \\
\hline Blood lactates increase & Cold skin & $P C W P \geq 15 \mathrm{mmHg}$ \\
\hline \multirow[t]{2}{*}{ Blood creatinine increase } & Diuresis $<30 \mathrm{~mL} / \mathrm{h}$ & \\
\hline & Lactates $>2.0 \mathrm{mmol} / \mathrm{L}$ & \\
\hline
\end{tabular}

$\mathrm{SBP}$ — systolic blood pressure; $\mathrm{Cl}$ — cardiac index; PCWP — pulmonary capillary wedge pressure

severity, may result in multi-organ dysfunction and death [51].

Recently, the Society Cardiovascular Angiography and Intervention introduced a new classification in five stages for CS [52]:

- A: "at risk": patient without signs/symptoms of CS but at risk for it;

— B: "beginning": patient with hypotension and tachycardia, without hypoperfusion;

- C: "classic": when also hypoperfusion occurs and inotropes, vasopressors, or mechanical support are needed;

- D: "deteriorating": in cases of poor response to treatment in level " $\mathrm{C}$ " and worsening conditions;

- E: "extremis": patient with circulatory collapse with ongoing cardiopulmonary resuscitation or on ECMO.

Cardiogenic shock is caused more frequently by LV dysfunction, with MI accounting for more than $80 \%$ of cases of CS. In some cases, also right ventricular dysfunction or bi-ventricular dysfunction are responsible for CS. In spite of new technological developments, technical PCI improvements, and pharmacological management changes, $\mathrm{CS}$ is still affected by high mortality.

The use of PVAD has already changed the CS natural history, and although scientific data are still controversial, their use is recommended in the current international guidelines (Table 4) $[6,18,25,26,53,54]$ and supported by many expert users [55].
Cardiogenic schock may rapidly become irreversible, and for this reason the timing of intervention might influence the efficacy of any device. Nowadays, many factors have been identified as potential mortality predictors in the setting of CS [56-58], and some patients with advanced CS are unlikely to recover even with a short time for intervention and with the strongest PVAD. For this reason, an important step for PVAD selection is represented by the early recognition of conditions defining the "futility" for the treatment.

\section{PVADs in refractory cardiac arrest}

The use of PVADs in specific situations such as refractory cardiac arrest is still controversial. Indeed, initial observational data about refractory cardiac arrest show the importance of early cardiac catheterization in comatose survivors without signs of STEMI [59]. Following this, AHA guidelines suggested emergent coronary angiogram for selected patients with cardiac arrest, who are comatose with electrical or hemodynamic instability [60].

However, those data were disproven by the more recent COACT trial $[61,62]$ : at 90 days and after 1-year follow-up, no significant differences in survival and major adverse cardiac events were found between patients undergoing immediate and delayed coronary angiography if signs of STEMI were not present. Around two thirds of the entire population had an underlying coronary artery disease, and only $30-40 \%$ of them underwent revascu- 
Table 4. Use of percutaneous ventricular assist device (PVAD) in cardiogenic shock according to international guidelines.

\begin{tabular}{|c|c|c|c|c|c|}
\hline PVAD & $\begin{array}{l}\text { Clinical } \\
\text { setting }\end{array}$ & Guidelines & $\begin{array}{l}\text { Recommenda- } \\
\text { tion class }\end{array}$ & $\begin{array}{l}\text { Level of } \\
\text { evidence }\end{array}$ & Recommendation \\
\hline \multirow[t]{7}{*}{ IABP } & Post MI CS & STEMI ACC/AHA 2013 & Ila & B & $\begin{array}{l}\text { Patients who do not quickly } \\
\text { stabilize with pharmacological } \\
\text { therapy }\end{array}$ \\
\hline & Post MI CS & HF ESC 2016 & Ila & $\mathrm{C}$ & $\begin{array}{l}\text { CS due to mechanical } \\
\text { complications of } \mathrm{MI}\end{array}$ \\
\hline & & STEMI ESC 2017 & & & \\
\hline & & SCA NSTE ESC 2015 & & & \\
\hline & CS & HF ESC 2016 & III & $\mathrm{B}$ & Routine use of IABP is not \\
\hline & & STEMI ESC 2017 & & & \\
\hline & & SCA NSTE ESC 2015 & & & \\
\hline \multirow[t]{3}{*}{$\begin{array}{l}\text { MECHANICAL } \\
\text { SUPPORT }\end{array}$} & CS & HF ESC 2016 & Ilb & $\mathrm{C}$ & $\begin{array}{l}\text { May be considered in } \\
\text { refractory CS depending on } \\
\text { patient age, comorbidities, } \\
\text { and neurological function }\end{array}$ \\
\hline & & HF ACC/AHA 2013 & Ila & $\mathrm{B}$ & \\
\hline & Post MI CS & $\begin{array}{c}\text { Myocardial } \\
\text { Revascularization ESC } \\
2018\end{array}$ & Ilb & C & $\begin{array}{l}\text { In selected patients with acute } \\
\text { coronary syndrome and CS, } \\
\text { mechanical circulatory support } \\
\text { may be considered, } \\
\text { depending on patient age, } \\
\text { comorbidities, neurological } \\
\text { function, and the prospects } \\
\text { for long-term survival and } \\
\text { predicted quality of life }\end{array}$ \\
\hline
\end{tabular}

Classes of recommendations and levels of evidence as for Table 1. CS — cardiogenic shock; IABP — intra-aortic balloon pump; $\mathrm{MI}$ - myocardial infarction

larization treatment (either PCI or coronary artery bypass grafting), while conservative management was selected for the remaining $60-70 \%$. Interestingly, CS was responsible for $11.7 \%$ and $8.4 \%$ of deaths in the immediate invasive and delayed invasive groups, respectively. Multi-organ failure leading to death occurred in $8.5 \%$ and $14.5 \%$ of immediate invasive and delayed invasive patients, respectively. Moreover, around $2-3 \%$ of screened patients were excluded due to hemodynamic instability unresponsive to medical therapy and some patients switched from the delayed to the immediate group due to shock development. These data raise the question about the possible usefulness of PVADs in the setting of cardiac arrest without STEMI signs.

On the other hand, among patients experiencing cardiac arrest in the context of STEMI, CS is more likely to occur as compared to those without cardiac arrest (36.7\% vs. $5.9 \%, \mathrm{p}<0.001)$ [63]. Moreover, those with CS and cardiac arrest show higher mortality than those without cardiac arrest ( $47.3 \%$ vs. $25.1 \%$, p < 0.001). Overall, data suggest that PVADs should be considered in cases of car- diac arrest independently of diagnosis at admission (ischemic or not), although no data suggesting who might benefit more are currently available.

The AHA Guidelines for Cardiopulmonary Resuscitation and Emergency Cardiovascular Care published in 2010 indicate that ECMO may be considered in settings where it is readily available, blood flow interruption following arrest is brief, and the underlying condition leading to arrest is reversible [64]. However, the 2019 focus update does not recommend the routine use of ECMO for patients with cardiac arrest [65].

The most important outcome determinant in the context of cardiac arrest is represented by the time to chest compression that should begin immediately or at the latest within $5 \mathrm{~min}$ [66]. Following cardiac arrest and cardiopulmonary resuscitation (CPR) initiation, the ECMO team should be alerted and already prepared in the very early phases: in a propensity-matched analysis, ECMO implantation within 21 min of CPR initiation in out-of-hospital cardiac arrest patients provided better neurological outcomes [67]. Such data support early activation 
of the ECMO team and suggest avoidance of refractory cardiac arrest onset (defined as the lack of return of spontaneous circulation after $30 \mathrm{~min}$ of appropriate CPR in the absence of hypothermia), although previous data report beneficial effects also in prolonged CPR and delayed ECMO implantation [68-70], provided that trained personnel are available [71]. In this perspective, time from cardiac arrest to CPR and then to ECMO is of utmost importance. Patients with initial rhythm of ventricular tachycardia/fibrillation and witnessed arrest are the best candidates for ECMO, while cases with asystole as initial rhythm, total cardiac arrest time $>60 \mathrm{~min}$, and significant comorbidities affecting life-expectancy should be carefully evaluated by the Heart Team as possible futile cases.

Promising results have been demonstrated also with Impella $\mathrm{CP}$ or Impella $\mathrm{CP}+\mathrm{RP}$ in small case series or case reports [72, 73].

\section{Futility}

Futility should always be taken into account when evaluating the best treatment option for cardiac arrest, especially when PVAD placement is required. Currently, a number of different scores have been proposed to predict the survival of patients under ECMO treatment after cardiac arrest, such as SAVE score [74], ENCOURAGE score [75], and the ECMO score [76].

Recently, a simple rule consisting in nonshockable rhythm, unwitnessed arrest, and age $\geq 80$ years has been proposed to predict futile resuscitation for out-of-hospital cardiac arrest [77]. However, it seems a simplistic approach, and some other well-known survival predictors should probably be considered (e.g. no-flow duration, initial cardiac rhythm, presence of gasping, etc.). Additional considerations should address the time for ECMO center transfer (in case of centers without ECMO capabilities) if the predicted duration of needed support is compatible with available technology or if the optimal window for any PVAD has already expired and the patient's wishes should be considered. A recent Panel Expert paper proposed the following inclusion and exclusion criteria for ECMO therapy selection [78].

Inclusion criteria:

— age < 70 years;

- shockable rhythm as initial rhythm;

- witnessed arrest;

- bystander CPR within 5 min;

- failure to achieve return of spontaneous circulation within 5 min of CPR start.
Exclusion criteria:

- asystole as initial rhythm;

- unwitnessed arrest;

- total cardiac arrest time $>60 \mathrm{~min}$;

- pre-existing severe neurological or systemic disease;

- contraindications to anticoagulation;

- acute aortic dissection;

- suspicion of shock due to hemorrhage of other non-cardiac causes;

- known "do not resuscitate" status.

However, a multidisciplinary (e.g. cardiologist, cardiac surgeon, heart failure specialist, intensivist, palliative care specialist, etc.) case-by-case decision-making process should be adopted whenever feasible [79].

\section{PVADs in cardiogenic shock}

The most used PVADs for the CS or for refractory cardiac arrest are the IABP, Impella, and ECMO (Fig. 2), sometimes combined (ECMO + Impella or IABP). PVAD are mainly used in this setting as a bridge to recovery, to decision, or, more rarely, to transplant.

\section{IABP and cardiogenic shock}

In the context of CS due to acute coronary syndrome, current European guidelines do not recommend the systematic use of IABP (Table 4). It should be considered only in cases of hemodynamic instability and cardiogenic shock due to acute coronary syndrome mechanical complications (Class IIa, LoE: C) and in those with acute severe myocarditis [6]. These guidelines are mainly based on the IABP-SHOCK II trial results, which randomized 600 patients with MI complicated by CS to routine IABP versus no routine IABP [80]. All patients were expected to undergo early revascularization. No difference in all-cause mortality (IABP group $39.7 \%$ vs. control group $41.7 \%, p=0.69$ ) or any secondary endpoints was found at 30-day and 12-month follow-up. Of note, in this trial, patients of the "no routine" IABP arm received IABP in 10\% of cases, and for other mechanical support devices in as many as $7.4 \%$ of cases. Moreover, the mortality rate itself was relatively low as compared to the SHOCK trial (30-day mortality rate of $46.7 \%$ ), making the study underpowered. In addition, the CS definition did not take into account cardiac index or wedge pressure, as compared to the SHOCK trial.

Recently, the 6-year follow-up confirmed the negative results for both the intention-to-treat and for the as-treated population. These data led to 


\begin{tabular}{|c|c|c|c|c|c|c|c|}
\hline & Baseline & IABP & Imp & ella & ECMO & IABP + ECMO & Impella + ECMO \\
\hline French & & $8-9$ & $13(2.5)$ & $14(\mathrm{CP})$ & $\begin{array}{l}14-19(\mathrm{~A}) \\
17-21(\mathrm{~V})\end{array}$ & $\begin{array}{c}8-9 \text { (IABP) } \\
+14-19(\mathrm{~A}) \\
17-21(\mathrm{~V})\end{array}$ & $\begin{array}{c}13-14 \text { (Impella) } \\
+14-19(\mathrm{~A}) \\
17-21(\mathrm{~V})\end{array}$ \\
\hline HR, bpm & 100 & 100 & 100 & 100 & 100 & 100 & $100 *$ \\
\hline PCWP, $\mathrm{mmHg}$ & 23 & $-4 \%$ & $-9 \%$ & $-13 \%$ & $+17 \%$ & $+13 \%$ & $+9 \% *$ \\
\hline AoP, $\mathrm{mmHg}$ & $81 / 46(61)$ & $+2 \%$ & $+8 \%$ & $+15 \%$ & $+28 \%$ & $+31 \%$ & $+39 \% *$ \\
\hline $\mathrm{CO}, \mathrm{L} / \mathrm{min}$ & 3.93 & $+5 \%$ & $+13 \%$ & $+28 \%$ & $+43 \%$ & $+48 \%$ & $+60 \% *$ \\
\hline CPO, watts & 0.53 & $+7 \%$ & $+21 \%$ & $+34 \%$ & $+81 \%$ & $+91 \%$ & $+118 \% *$ \\
\hline $\begin{array}{l}\text { PVA, } \mathrm{mmHg} \\
\times \mathrm{mL}\end{array}$ & 4989 & $-3 \%$ & $-7 \%$ & $-13 \%$ & $+16 \%$ & $+14 \%$ & $+7 \% *$ \\
\hline $\mathrm{CBF}, \mathrm{mL} / \mathrm{min} / \mathrm{g}$ & 0.09 & $+10 \%$ & $+10 \%$ & $+20 \%$ & $+40 \%$ & $+50 \%$ & $+70 \%$ * \\
\hline $\begin{array}{l}\text { Approved } \\
\text { duration of } \\
\text { assistance }\end{array}$ & & $\begin{array}{l}\text { No limitations } \\
\text { (vascular } \\
\text { complications } \\
\text { increases } \\
\text { after } 2 \text { days) }\end{array}$ & $\begin{array}{l}4 \text { day } \\
5 \text { day }\end{array}$ & $\begin{array}{l}\text { (US) } \\
\text { s (EU) }\end{array}$ & $\begin{array}{l}\text { Usually } \\
<7 \text { days [1] } \\
\text { (poor survival } \\
\text { if }>7 \text { days) }\end{array}$ & $\begin{array}{l}\text { See IABP } \\
\text { and ECMO } \\
\text { columns }\end{array}$ & $\begin{array}{l}\text { See Impella } \\
\text { and ECMO } \\
\text { columns }\end{array}$ \\
\hline
\end{tabular}

Figure 2. Main characteristics and cardiac effects of intra-aortic balloon pump (IABP), Impella, extracorporeal membrane oxygenation (ECMO), and possible combinations strategies. All values are calculated with the Harvi Professor software; HR — heart rate; PCWP — pulmonary capillary wedge pressure; AoP — aortic pressure; CO — cardiac output; CPO — cardiac power output; PVA — pressure-volume area; CBF — coronary blood flow; *values are calculated considering Impella 2.5 combined with ECMO. For reference [1] see dedicated reference list.

a decrease in IABP use in favor of Impella and ECMO [81]. Accordingly, it makes sense to consider IABP in specific conditions like mechanical complications and earlier shock stages (pre-shock), as shown in Figure 3. It has been successfully used also in some cases of arrhythmic storm in ischemic patients [82, 83].

\section{Impella and cardiogenic shock}

Two randomized trials, ISAR-SHOCK [84] and IMPRESS [85], compared the use of IABP and Impella in patients experiencing acute MI complicated by CS, and no differences in the overall 30 -day and 6-month mortality were found. Of note, both studies were underpowered for mortality. In the ISAR-SHOCK, Impella was implanted after coronary revascularization, while in the IMPRESS the implantation timing was left to the operators' choice, although more recent data suggest an early Impella positioning in patients with CS [86, 87]. Moreover, two recent meta-analyses confirmed the lack of benefit in terms of mortality, although an improvement in arterial lactate and mean blood pressure was found $[88,89]$. In the specific scenario of acute myocarditis, the prolonged use of Impella, called "PROPELLA", has recently been proposed, but it still needs to be investigated on large groups of patients [34].

In general, available data do not support the routine use of Impella in patients with CS. Accordingly, its indication should be evaluated in the frame of local CS and careful case by case decisions [90]. In this regard, patients with severe LV dysfunction and persistent systemic hypoperfusion are those who may theoretically benefit from Impella LV support provided that futility has been ruled out (Fig. 3). Greater attention should be addressed to refractory CS or to biventricular dysfunction because those patients may not benefit from Impella left support alone, but they have been proposed to be approached using a combination of the Impella right and left system (Fig. 3) [91, 92].

\section{ECMO and cardiogenic shock}

In the field of $\mathrm{CS}$, much broader experience has been gained with ECMO. It has been mostly studied in the context of CS following STEMI, 


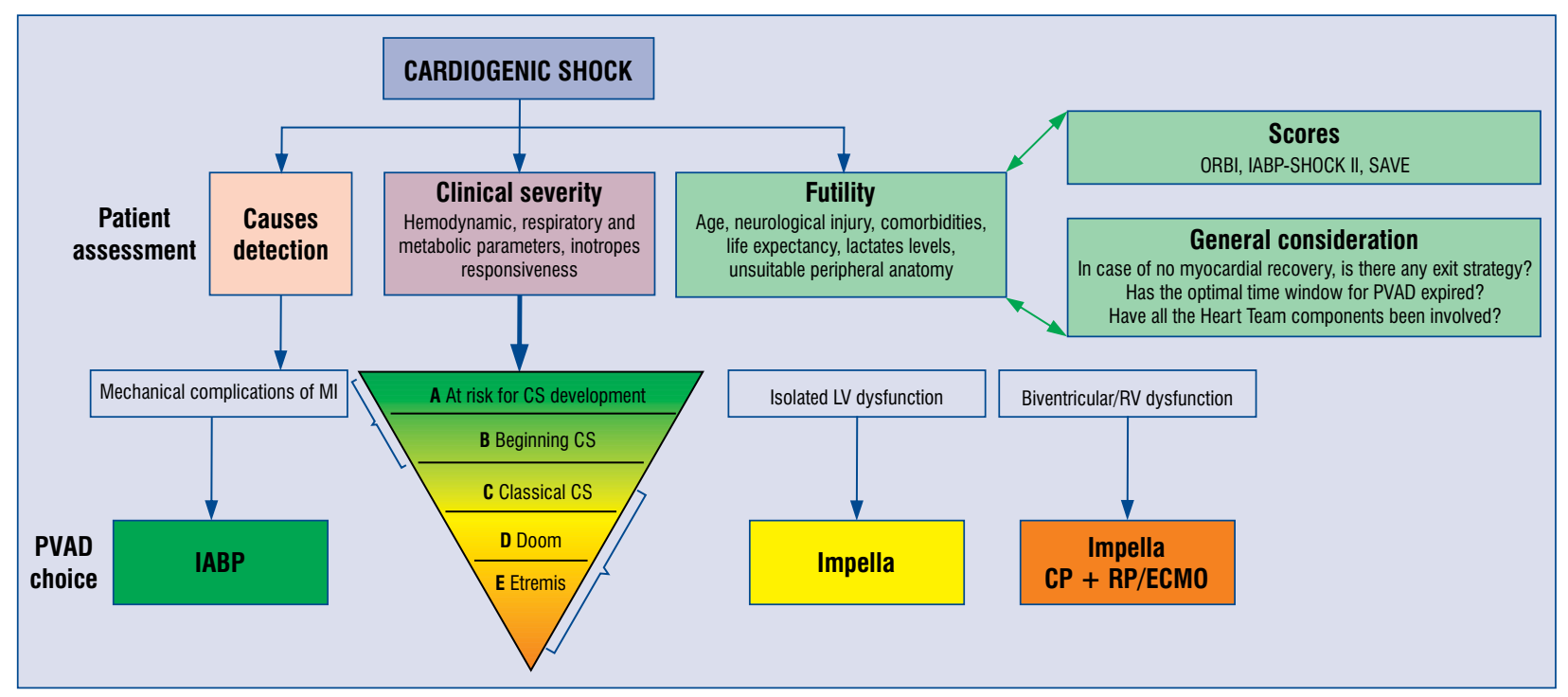

Figure 3. Proposed pre-procedural assessment and percutaneous ventricular assistance device (PVAD) choice in the context of cardiogenic shock (CS); IABP — intra-aortic balloon pump; MI - myocardial infarction; LV — left ventricle; $\mathrm{RV}$ - right ventricle; ECMO - extracorporeal membrane oxygenation.

acute myocarditis, post-cardiotomy, and in refractory cardiac arrest.

Retrospective data from Sheu et al. [93] and Chung et al. [94] demonstrated that the use of ECMO during primary PCI in patients admitted for STEMI complicated by CS may improve the 30 -day outcome with an overall mortality of $43 \%$.

In the setting of acute myocarditis complicated by $\mathrm{CS}$, the ECMO has been used as a "bridge to recovery", with a survival rate around $70 \%$, and the long-term outcomes were similar to those who experienced acute myocarditis without hemodynamic compromise [95-97].

A recent meta-analysis demonstrated a significant mortality benefit with ECMO in both cardiac arrest patients $(\mathrm{n}=3098)$ and in patients with CS due to MI $(\mathrm{n}=235)$. In cardiac arrest, the use of ECMO was associated with an absolute increase in 30-day survival of $13 \%$ compared with patients in whom ECMO was not used, whereas in CS ECMO showed a $33 \%$ greater 30-day survival compared with IABP but no difference when compared with TandemHeart/Impella [98].

Currently, the following trials are underway in order to improve CS management:

- ECLS-SHOCK (NCT03637205), ECMO-CS (NCT02301819), and EURO-SHOCK (NCT03813134): ECMO vs. control in severe CS complicating MI;

- DANGER (NCT01633502): Impella vs. control in severe CS complicating MI;

- REVERSE (NCT03431467), ECMO combined with Impella CP vs. ECMO alone in CS;
- PRAGUE OHCA (NCT01511666), ECMO vs. control in refractory out-of-hospital cardiac arrest.

While waiting for the results of such trials, ECMO should be regarded as an important tool in patients with more advanced CS and in those with biventricular failure (Fig. 3).

\section{PVAD combination strategies}

Although the use of ECMO is an established therapy option in severe CS, mortality is high. The lack of LV unloading and the increase of afterload are the main limitations for ECMO. These limitations together with the peculiar characteristics and the different hemodynamic effects of each device lead to combination strategies (Fig. 2) in order to improve outcomes in critical settings.

A recent meta-analysis demonstrated beneficial effects of LV unloading (achieved with IABP, Impella, or TandemHeart) on top of ECMO in the setting of CS [99]. The greatest source of data about the combination of IABP and ECMO is the Japanese database, which demonstrated a higher in-hospital and 28-day survival rate in those with both devices as compared to ECMO alone [100]. This might be explained by the counterbalance hemodynamic effect of IABP on ECMO, specifically afterload and myocardial oxygen demand reductions. Moreover, an additional positive IABP effect might be related to coronary perfusion increase. Similar results were achieved with the use of Impella on top of ECMO [41]. However, all available 


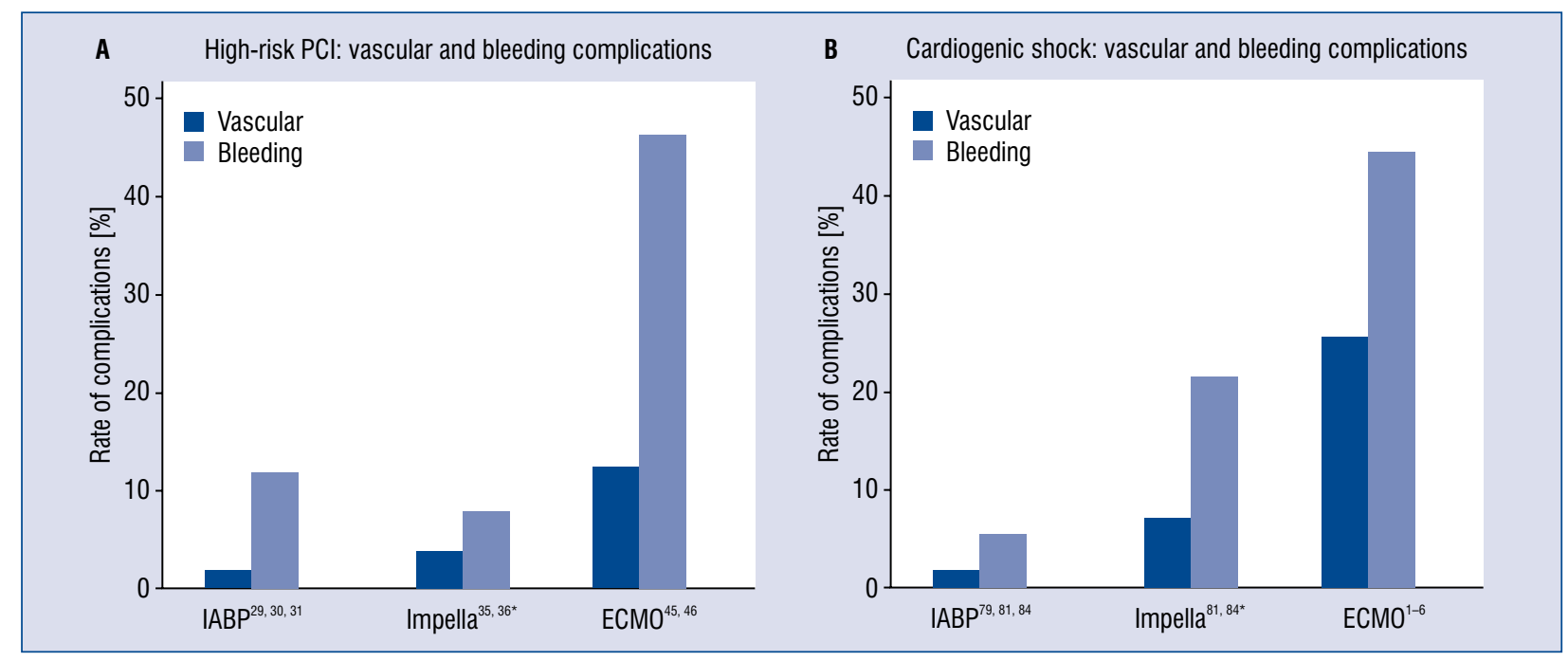

Figure 4. A. Access-site-related vascular and bleeding complication rate in high-risk percutaneous coronary intervention according to different percutaneous ventricular assist device (averaged mean value); B. Access-site-related vascular and bleeding complication rate in cardiogenic shock according to different percutaneous ventricular assist device (averaged mean value). Note: Major and minor vascular/bleeding complications are pooled together; $\mathrm{PCl}$ - percutaneous coronary intervention; IABP — intra-aortic balloon pump; ECMO - extracorporeal membrane oxygenation; * data from both Impella 2.5 and CP were considered. For references [1-6] see dedicated reference list.

data are retrospective, and possible complications should be considered when evaluating combination therapy (e.g. hemolysis, bleeding/vascular complications); consequently, randomized studies are needed to better investigate the beneficial effect of such strategies.

Finally, over the last few years, the Impella family has been enriched with the Impella RP pump. It delivers blood from the inferior vena cava (inlet area), through the cannula, to the pulmonary artery (outlet area). It has United States Food and Drug Administration approval and is indicated for providing right ventricular support for up to 14 days in patients developing acute right heart failure or decompensation following LV assist device implantation, MI, heart transplantation, or open-heart surgery. The main contraindications are right-side valvular heart disease, mural thrombus of the right atrium, or vena cava and anatomic conditions precluding insertion of the pump. Currently, data about the use of Impella RP and Bi-Pella are scarce. A retrospective study on 20 patients implanting the Bi-Pella demonstrated its feasibility and its efficacy, although CS causes were heterogeneous and in-hospital mortality was $50 \%$ [101].

At the same time, simultaneous initiation of support with Impella CP and Impella RP has been associated with improved survival outcomes as compared with staged initiation of support, and this would offer a stepwise weaning of univentricular or biventricular support [102].

\section{Vascular and bleeding complications with PVADs}

The large-bore size of the PVAD's sheath or cannula has the potential to induce access-siterelated vascular complications. The occurrence of such vascular complications may cause acute anemia, transfusions, or urgent vascular surgery. Such events obviously have the potential to jeopardize the clinical course after effective high-risk PCI or during CS after initial effective stabilization. Thus, meticulous attention should be paid during the pre-PCI work-out, during the vascular access instauration, and during the hemostasis phase $[33,103]$. Not surprisingly, data from the largest registries and trials show an increasing risk for vascular and bleeding issues correlated to the sheath size, with the IABP being the safest and the ECMO having the highest rate of complications (Fig. 4A, B). A recent sub-analysis of the CULPRIT-SHOCK trial showed that both ECMO and Impella treatments are predictors of bleeding events, and this, in turn, affects shortterm survival probability [104].

In addition, when a second access is required (e.g. coronary angiography, PCI), the choice between contralateral femoral or radial access should be considered. A study comparing transradial 
versus transfemoral secondary access for transcatheter aortic valve implantation has recently demonstrated a significant improvement in terms of vascular and bleeding complications in those using radial access as compared to femoral access [105]. Although no similar studies exist for PVADs, the experience from the transcatheter aortic valve implantation world might be applicable also to PVAD field. In this regard, a two-center experience with Impella and meticulous ancillary access and PVAD access hemostasis reported very promising safety results [10]. Consequently, the choice for the secondary access should be carefully evaluated according to the complexity of the procedure, the equipment available, and the operator's experience.

\section{Conclusions}

Percutaneous ventricular assistance devices are potentially useful tools for the management of critically ill patients, but many uncertainties exist regarding their clinical impact. Improved percutaneous techniques are making the catheterization laboratory an important location for PVAD implantation. Because different devices (with different mechanisms of action and anatomic requirement) are becoming more and more available, attempts to rationalize their selection in the context of local team expertise is pivotal.

Conflict of interest: Dr. Francesco Burzotta discloses to have been involved in advisory board meetings and having received speaker's fees from Abbott, Abiomed, Medtronic, and Biotronic. Dr. Cristina Aurigemma has been involved in advisory board activities by Abbott, Abiomed, Medtronic, and Biotronic. Dr. Carlo Trani discloses to have been involved in advisory board meetings and having received speaker's fees from Abbott, Abiomed, Medtronic, and Biotronic. Dr. Giulio Russo received fellowship training grant from EAPCI, sponsored by Edwards Life Sciences. Other authors have no conflicts of interest.

\section{References}

1. Stretch R, Sauer CM, Yuh DD, et al. National trends in the utilization of short-term mechanical circulatory support: incidence, outcomes, and cost analysis. J Am Coll Cardiol. 2014; 64(14): 1407-1415, doi: 10.1016/j.jacc.2014.07.958, indexed in Pubmed: 25277608.

2. Aurigemma C, Burzotta F, Russo G, et al. Definitions and clinical impact of revascularization completeness. Minerva Cardioangiol. 2018; 66(5): 594-599, doi: 10.23736/S0026-4725.18.04654-6, indexed in Pubmed: 29546745.
3. Romagnoli E, Burzotta F, Trani C, et al. EuroSCORE as predictor of in-hospital mortality after percutaneous coronary intervention. Heart. 2009; 95(1): 43-48, doi: 10.1136/hrt.2007.134114, indexed in Pubmed: 18208829.

4. Coluccia V, Burzotta F, Romagnoli E, et al. EuroSCORE predicts long-term mortality of unselected patients undergoing percutaneous coronary interventions. Int J Cardiol. 2013; 167(4): 1232-1236, doi: 10.1016/j.jicard.2012.03.149, indexed in Pubmed: 22503571.

5. Burzotta F, Trani C, Doshi SN, et al. Impella ventricular support in clinical practice: Collaborative viewpoint from a European expert user group. Int J Cardiol. 2015; 201: 684-691, doi: 10.1016/j. ijcard.2015.07.065, indexed in Pubmed: 26363632.

6. Burzotta F, Crea F. „Protected” PCI: time to act. Minerva Cardioangiol. 2018; 66(5): 547-550, doi: 10.23736/S00264725.18.04704-7, indexed in Pubmed: 29687701.

7. Généreux P, Palmerini T, Caixeta A, et al. Quantification and impact of untreated coronary artery disease after percutaneous coronary intervention: the residual SYNTAX (Synergy Between PCI with Taxus and Cardiac Surgery) score. J Am Coll Cardiol. 2012; 59(24): 2165-2174, doi: 10.1016/j.jacc.2012.03.010, indexed in Pubmed: 22483327.

8. O'Neill WW, Kleiman NS, Moses J, et al. A prospective, randomized clinical trial of hemodynamic support with Impella 2.5 versus intra-aortic balloon pump in patients undergoing high-risk percutaneous coronary intervention: the PROTECT II study. Circulation. 2012; 126(14): 1717-1727, doi: 10.1161/CIRCULATIONAHA.112.098194, indexed in Pubmed: 22935569.

9. De Silva K, Morton G, Sicard P, et al. Prognostic utility of BCIS myocardial jeopardy score for classification of coronary disease burden and completeness of revascularization. Am J Cardiol. 2013; 111(2): 172-177, doi: 10.1016/j.amjcard.2012.09.012, indexed in Pubmed: 23102883.

10. Burzotta F, Russo G, Ribichini F, et al. Long-Term outcomes of extent of revascularization in complex high risk and indicated patients undergoing impella-protected percutaneous coronary intervention: report from the roma-verona registry. J Interv Cardiol. 2019; 2019: 5243913, doi: 10.1155/2019/5243913, indexed in Pubmed: 31772533.

11. Russo G, Burzotta F, D'Amario D, et al. Hemodynamics and its predictors during Impella-protected PCI in high risk patients with reduced ejection fraction. Int J Cardiol. 2019; 274: 221-225, doi: 10.1016/j.ijcard.2018.07.064, indexed in Pubmed: 30057165.

12. Bergelson BA, Jacobs AK, Cupples LA, et al. Prediction of risk for hemodynamic compromise during percutaneous transluminal coronary angioplasty. Am J Cardiol. 1992; 70(20): 1540-1545, doi: 10.1016/0002-9149(92)90454-7, indexed in Pubmed: 1466320.

13. Leistner DM, Dietrich S, Erbay A, et al. Association of left ventricular end-diastolic pressure with mortality in patients undergoing percutaneous coronary intervention for acute coronary syndromes. Catheter Cardiovasc Interv. 2020; 96(4): E439-E446, doi: 10.1002/ccd.28839, indexed in Pubmed: 32141669.

14. Laschinger J, Grossi E, Cunningham J, et al. Adjunctive left ventricular unloading during myocardial reperfusion plays a major role in minimizing myocardial infarct size. J Thorac Cardiovasc Surg. 1985; 90(1): 80-85, doi: 10.1016/s0022-5223(19)38666-0.

15. Axelrod HI, Galloway AC, Murphy MS, et al. A comparison of methods for limiting myocardial infarct expansion during acute reperfusion--primary role of unloading. Circulation. 1987; 76(5 Pt 2): V28-V32, indexed in Pubmed: 3665016.

16. Santamore WP, Burkhoff D. Hemodynamic consequences of ventricular interaction as assessed by model analysis. 
Am J Physiol. 1991; 260(1 Pt 2): H146-H157, doi: 10.1152/ ajpheart.1991.260.1.H146, indexed in Pubmed: 1992793.

17. Kantrowitz A, Tjonneland S, Freed PS, et al. Initial clinical experience with intraaortic balloon pumping in cardiogenic shock. JAMA. 1968; 203(2): 113-118, indexed in Pubmed: 5694059.

18. Weber KT, Janicki JS. Intra-aortic balloon counterpulsation. Ann Thorac Surg. 1974; 17: 602.

19. Kern MJ, Aguirre F, Bach R, et al. Augmentation of coronary blood flow by intra-aortic balloon pumping in patients after coronary angioplasty. Circulation. 1993; 87(2): 500-511, doi: 10.1161/01.cir.87.2.500.

20. Yoshitani H, Akasaka T, Kaji S, et al. Effects of intra-aortic balloon counterpulsation on coronary pressure in patients with stenotic coronary arteries. Am Heart J. 2007; 154(4): 725-731, doi: 10.1016/j.ahj.2007.05.019, indexed in Pubmed: 17893000.

21. Takeuchi M, Nohtomi Y, Yoshitani H, et al. Enhanced coronary flow velocity during intra-aortic balloon pumping assessed by transthoracic Doppler echocardiography. J Am Coll Cardiol. 2004; 43(3): 368-376, doi: 10.1016/j.jacc.2003.08.047, indexed in Pubmed: 15013116.

22. Kern MJ, Aguirre FV, Tatineni S, et al. Enhanced coronary blood flow velocity during intraaortic balloon counterpulsation in critically ill patients. J Am Coll Cardiol. 1993; 21(2): 359-368, doi: 10.1016/0735-1097(93)90676-r, indexed in Pubmed: 8425999.

23. Basile E, Russo G, Leone AM. Principles of hemodynamics for mechanical circulatory support: patho-physiological key aspects of assisted PCI. Minerva Cardioangiol. 2018; 66(5): 600-605, doi: 10.23736/S0026-4725.18.04658-3, indexed in Pubmed: 29546747.

24. Sousa-Uva M, Neumann FJ, Ahlsson A, et al. ESC Scientific Document Group, ESC Scientific Document Group. 2018 ESC/ /EACTS Guidelines on myocardial revascularization. Eur Heart J. 2019; 40(2): 87-165, doi: 10.1093/eurheartj/ehy394, indexed in Pubmed: 30165437.

25. Ibanez B, James S, Agewall S, et al. ESC Scientific Document Group. 2017 ESC Guidelines for the management of acute myocardial infarction in patients presenting with ST-segment elevation: The Task Force for the management of acute myocardial infarction in patients presenting with ST-segment elevation of the European Society of Cardiology (ESC). Eur Heart J. 2018; 39(2): 119-177, doi: 10.1093/eurheartj/ehx393, indexed in Pubmed: 28886621.

26. Collet JP, Thiele H, Barbato E, et al. ESC Scientific Document Group. 2020 ESC Guidelines for the management of acute coronary syndromes in patients presenting without persistent ST-segment elevation. Eur Heart J. 2020 [Epub ahead of print], doi: 10.1093/eurheartj/ehaa575, indexed in Pubmed: 32860058.

27. Levine GN, Bates ER, Blankenship JC, et al. American College of Cardiology Foundation; American Heart Association Task Force on Practice Guidelines; Society for Cardiovascular Angiography and Interventions. 2011 ACCF/AHA/SCAI Guideline for Percutaneous Coronary Intervention. A report of the American College of Cardiology Foundation/American Heart Association Task Force on Practice Guidelines and the Society for Cardiovascular Angiography and Interventions. J Am Coll Cardiol. 2011; 58(24): e44-122, doi: 10.1016/j.jacc.2011.08.007, indexed in Pubmed: 22070834 .

28. Briguori C, Sarais C, Pagnotta P, et al. Elective versus provisional intra-aortic balloon pumping in high-risk percutaneous transluminal coronary angioplasty. Am Heart J. 2003; 145(4): 700-707, doi: 10.1067/mhj.2003.14, indexed in Pubmed: 12679768.
29. Mishra S, Chu WW, Torguson R, et al. Role of prophylactic intra-aortic balloon pump in high-risk patients undergoing percutaneous coronary intervention. Am J Cardiol. 2006; 98(5): 608-612, doi: 10.1016/j.amjcard.2006.03.036, indexed in Pubmed: 16923445 .

30. Briguori C, Airoldi F, Chieffo A, et al. Elective versus provisional intraaortic balloon pumping in unprotected left main stenting. Am Heart J. 2006; 152(3): 565-572, doi: 10.1016/j. ahj.2006.02.024, indexed in Pubmed: 16923432.

31. Curtis JP, Rathore SS, Wang Y, et al. Use and effectiveness of intra-aortic balloon pumps among patients undergoing high risk percutaneous coronary intervention: insights from the National Cardiovascular Data Registry. Circ Cardiovasc Qual Outcomes. 2012; 5(1): 21-30, doi: 10.1161/CIRCOUTCOMES.110.960385, indexed in Pubmed: 22147887.

32. Perera D, Stables R, Clayton T, et al. BCIS-1 Investigators, BCIS-1 Investigators. Elective intra-aortic balloon counterpulsation during high-risk percutaneous coronary intervention: a randomized controlled trial. JAMA. 2010; 304(8): 867-874, doi: 10.1001/jama.2010.1190, indexed in Pubmed: 20736470.

33. Perera D, Stables R, Clayton T, et al. BCIS-1 Investigators. Longterm mortality data from the balloon pump-assisted coronary intervention study (BCIS-1): a randomized, controlled trial of elective balloon counterpulsation during high-risk percutaneous coronary intervention. Circulation. 2013; 127(2): 207-212, doi: 10.1161/CIRCULATIONAHA.112.132209, indexed in Pubmed: 23224207.

34. Burzotta F, Russo G, Previ L, et al. Impella: pumps overview and access site management. Minerva Cardioangiol. 2018; 66(5): 606-611, doi: 10.23736/S0026-4725.18.04703-5, indexed in Pubmed: 29687700.

35. Tschöpe C, Van Linthout S, Klein O, et al. Mechanical Unloading by Fulminant Myocarditis: LV-IMPELLA, ECMELLA, BIPELLA, and PROPELLA Concepts. J Cardiovasc Transl Res. 2019; 12(2): 116-123, doi: 10.1007/s12265-018-9820-2, indexed in Pubmed: 30084076.

36. Buono A, Ielasi A, De Blasio G, et al. „Shock-Pella”: Combined management of an undilatable ostial left circumflex stenosis in a complex high-risk interventional procedure patient. Cardiol J. 2020; 27(4): 427-428, doi: 10.5603/CJ.2020.0112, indexed in Pubmed: 32929704.

37. Sjauw KD, Konorza T, Erbel R, et al. Supported high-risk percutaneous coronary intervention with the Impella 2.5 device the Europella registry. J Am Coll Cardiol. 2009; 54(25): 2430-2434, doi: 10.1016/j.jacc.2009.09.018, indexed in Pubmed: 20082934.

38. Maini B, Naidu SS, Mulukutla S, et al. Real-world use of the Impella 2.5 circulatory support system in complex high-risk percutaneous coronary intervention: the USpella Registry. Catheter Cardiovasc Interv. 2012; 80(5): 717-725, doi: 10.1002/ccd.23403, indexed in Pubmed: 22105829.

39. Massetti M, Gaudino M, Crea F. How to transform peripheral extracorporeal membrane oxygenation in the simplest midterm paracorporeal ventricular assist device. Int J Cardiol. 2013; 166(3): 551-553, doi: 10.1016/j.ijcard.2013.01.271, indexed in Pubmed: 23462637.

40. Meani P, Gelsomino S, Natour E, et al. Modalities and effects of left ventricle unloading on extracorporeal life support: a review of the current literature. Eur J Heart Fail. 2017; 19 Suppl 2: 84-91, doi: 10.1002/ejhf.850, indexed in Pubmed: 28470925.

41. Pappalardo F, Schulte C, Pieri M, et al. Concomitant implantation of Impella on top of veno-arterial extracorporeal membrane 
oxygenation may improve survival of patients with cardiogenic shock. Eur J Heart Fail. 2017; 19(3): 404-412, doi: 10.1002/ ejhf.668, indexed in Pubmed: 27709750.

42. Bignon M, Roule V, Dahdouh Z, et al. Percutaneous balloon atrioseptostomy for left heart discharge in extracorporeal life support patients with persistent pulmonary edema. J Interv Cardiol. 2012; 25(1): 62-67, doi: 10.1111/j.1540-8183.2011.00681.x, indexed in Pubmed: 22050190.

43. Danial P, Hajage D, Nguyen LS, et al. Percutaneous versus surgical femoro-femoral veno-arterial ECMO: a propensity score matched study. Intensive Care Med. 2018; 44(12): 2153 -2161, doi: 10.1007/s00134-018-5442-Z, indexed in Pubmed: 30430207.

44. Shammas N, Roberts S, Early G. Extracorporeal membrane oxygenation for unprotected left main stenting in a patient with totally occluded right coronary artery and severe left ventricular. J Invasive Cardiol. 2002; 14: 756-759, indexed in Pubmed: 12454340 .

45. Vainer J, van Ommen V, Maessen J, et al. Elective high-risk percutaneous coronary interventions supported by extracorporeal life support. Am J Cardiol. 2007; 99(6): 771-773, doi: 10.1016/j. amjcard.2006.10.034, indexed in Pubmed: 17350362.

46. Shaukat A, Hryniewicz-Czeneszew K, Sun B, et al. Outcomes of extracorporeal membrane oxygenation support for complex high-risk elective percutaneous coronary interventions: a single-center experience and review of the literature. J Invasive Cardiol. 2018; 30(12): 456-460, indexed in Pubmed: 30504514.

47. Ponikowski P, Voors A, Anker S, et al. ESC Scientific Document Group. 2016 ESC Guidelines for the diagnosis and treatment of acute and chronic heart failure: The Task Force for the diagnosis and treatment of acute and chronic heart failure of the European Society of Cardiology (ESC)Developed with the special contribution of the Heart Failure Association (HFA) of the ESC. Eur Heart J. 2016; 37(27): 2129-2200, doi: 10.1093/eurheartj/ ehw128.

48. Thiele H, Zeymer U, Neumann FJ, et al. Intraaortic Balloon Pump in cardiogenic shock II (IABP-SHOCK II) trial investigators, IABP-SHOCK II Trial Investigators. Intraaortic balloon support for myocardial infarction with cardiogenic shock. N Engl J Med. 2012; 367(14): 1287-1296, doi: 10.1056/NEJMoa1208410, indexed in Pubmed: 22920912.

49. Hochman JS, Sleeper LA, Webb JG, et al. Early revascularization in acute myocardial infarction complicated by cardiogenic shock. SHOCK Investigators. Should We Emergently Revascularize Occluded Coronaries for Cardiogenic Shock. N Engl J Med. 1999; 341(9): 625-634, doi: 10.1056/NEJM199908263410901, indexed in Pubmed: 10460813.

50. Zeitouni M, Akin I, Desch S, et al. CULPRIT-SHOCK Investigators. PCI Strategies in Patients with Acute Myocardial Infarction and Cardiogenic Shock. N Engl J Med. 2017; 377(25): 2419-2432, doi: 10.1056/NEJMoa1710261, indexed in Pubmed: 29083953.

51. Chioncel O, Parissis J, Mebazaa A, et al. Epidemiology, pathophysiology and contemporary management of cardiogenic shock - a position statement from the Heart Failure Association of the European Society of Cardiology. Eur J Heart Fail. 2020; 22(8): 1315-1341, doi: 10.1002/ejhf.1922, indexed in Pubmed: 32469155.

52. Baran DA, Grines CL, Bailey S, et al. SCAI clinical expert consensus statement on the classification of cardiogenic shock: This document was endorsed by the American College of Cardiology (ACC), the American Heart Association (AHA), the Society of Critical Care
Medicine (SCCM), and the Society of Thoracic Surgeons (STS) in April 2019. Catheter Cardiovasc Interv. 2019; 94(1): 29-37, doi: 10.1002/ccd.28329, indexed in Pubmed: 31104355.

53. O'Gara P, Kushner F, Ascheim D, et al. 2013 ACCF/AHA Guideline for the Management of ST-Elevation Myocardial Infarction. J Am Coll Cardiol. 2013; 61(4): e78-e140, doi: 10.1016/j. jacc.2012.11.019.

54. Yancy CW, Jessup M, Bozkurt B, et al. American College of Cardiology Foundation; American Heart Association Task Force on Practice Guidelines. 2013 ACCF/AHA guideline for the management of heart failure: a report of the American College of Cardiology Foundation/American Heart Association Task Force on Practice Guidelines. J Am Coll Cardiol. 2013; 62(16): e147-239, doi: 10.1016/j.jacc.2013.05.019, indexed in Pubmed: 23747642.

55. Thiele H, Ohman EM, de Waha-Thiele S, et al. Management of cardiogenic shock complicating myocardial infarction: an update 2019. Eur Heart J. 2019; 40(32): 2671-2683, doi: 10.1093/eurheartj/ehz363, indexed in Pubmed: 31274157.

56. Sanborn TA, Sleeper LA, Bates ER, et al. Impact of thrombolysis, intra-aortic balloon pump counterpulsation, and their combination in cardiogenic shock complicating acute myocardial infarction: a report from the SHOCK Trial Registry. SHould we emergently revascularize Occluded Coronaries for cardiogenic shocK? J Am Coll Cardiol. 2000; 36(3 Suppl A): 1123-1129, doi: 10.1016/s0735-1097(00)00875-5, indexed in Pubmed: 10985715.

57. Sleeper LA, Reynolds HR, White HD, et al. A severity scoring system for risk assessment of patients with cardiogenic shock: a report from the SHOCK Trial and Registry. Am Heart J. 2010; 160(3): 443-450, doi: 10.1016/j.ahj.2010.06.024, indexed in Pubmed: 20826251.

58. Harjola VP, Lassus J, Sionis A, et al. CardShock Study Investigators, GREAT network. Clinical picture and risk prediction of short-term mortality in cardiogenic shock. Eur J Heart Fail. 2015; 17(5): 501-509, doi: 10.1002/ejhf.260, indexed in Pubmed: 25820680.

59. Hollenbeck RD, McPherson JA, Mooney MR, et al. Early cardiac catheterization is associated with improved survival in comatose survivors of cardiac arrest without STEMI. Resuscitation. 2014; 85(1): 88-95, doi: 10.1016/j.resuscitation.2013.07.027, indexed in Pubmed: 23927955.

60. Callaway CW, Donnino MW, Fink EL, et al. Part 8: post-cardiac arrest care: 2015 American Heart Association guidelines update for cardiopulmonary resuscitation and emergency cardiovascular care. Circulation. 2015; 132(18 Suppl 2): S465-S482, doi: 10.1161/CIR.0000000000000262, indexed in Pubmed: 26472996.

61. Lemkes J, Janssens G, Hoeven Nv, et al. Coronary Angiography after Cardiac Arrest without ST-Segment Elevation. N Engl J Med. 2019; 380(15): 1397-1407, doi: 10.1056/nejmoa1816897.

62. Janssens GN, van der Hoeven NW, Lemkes JS, et al. 1-Year Outcomes of Delayed Versus Immediate Intervention in Patients With Transient ST-Segment Elevation Myocardial Infarction. JACC Cardiovasc Interv. 2019; 12(22): 2272-2282, doi: 10.1016/j. jcin.2019.07.018, indexed in Pubmed: 31488353.

63. Tyler J, Henry J, Garberich R, et al. The impact of cardiac arrest and cardiogenic shock on outcomes in ST-elevation myocardial infarction. J Am Coll Cardiol. 2019; 73(9): 167, doi: 10.1016/ /s0735-1097(19)30775-2.

64. Cave DM, Gazmuri RJ, Otto CW, et al. Part 7: CPR techniques and devices: 2010 American Heart Association Guidelines for Cardiopulmonary Resuscitation and Emergency Cardiovascular Care. Circulation. 2010; 122(18 Suppl 3): S720-S728, doi: 
10.1161/CIRCULATIONAHA.110.970970, indexed in Pubmed: 20956223

65. Panchal AR, Berg KM, Hirsch KG, et al. 2019 American Heart Association Focused Update on Advanced Cardiovascular Life Support: Use of Advanced Airways, Vasopressors, and Extracorporeal Cardiopulmonary Resuscitation During Cardiac Arrest: An Update to the American Heart Association Guidelines for Cardiopulmonary Resuscitation and Emergency Cardiovascular Care. Circulation. 2019; 140(24): e881-e894, doi: 10.1161/ CIR.0000000000000732, indexed in Pubmed: 31722552.

66. Rajan S, Wissenberg M, Folke F, et al. Association of bystander cardiopulmonary resuscitation and survival according to ambulance response times after out-of-hospital cardiac arrest. Circulation. 2016; 134(25): 2095-2104, doi: 10.1161/CIRCULATIONAHA.116.024400, indexed in Pubmed: 27881566.

67. Kim SuJ, Jung JS, Park JH, et al. An optimal transition time to extracorporeal cardiopulmonary resuscitation for predicting good neurological outcome in patients with out-of-hospital cardiac arrest: a propensity-matched study. Crit Care. 2014; 18(5): 535, doi: 10.1186/s13054-014-0535-8, indexed in Pubmed: 25255842.

68. Chen YS, Chao A, Yu HY, et al. Analysis and results of prolonged resuscitation in cardiac arrest patients rescued by extracorporeal membrane oxygenation. J Am Coll Cardiol. 2003; 41(2): 197-203, doi: 10.1016/s0735-1097(02)02716-x, indexed in Pubmed: 12535808.

69. Chen YS, Lin JW, Yu HY, et al. Cardiopulmonary resuscitation with assisted extracorporeal life-support versus conventional cardiopulmonary resuscitation in adults with in-hospital cardiac arrest: an observational study and propensity analysis. Lancet. 2008; 372(9638): 554-561, doi: 10.1016/S0140-6736(08)60958-7, indexed in Pubmed: 18603291.

70. Maekawa K, Tanno K, Hase M, et al. Extracorporeal cardiopulmonary resuscitation for patients with out-of-hospital cardiac arrest of cardiac origin: a propensity-matched study and predictor analysis. Crit Care Med. 2013; 41(5): 1186-1196, doi: 10.1097/ CCM.0b013e31827ca4c8, indexed in Pubmed: 23388518.

71. Spangenberg T, Meincke F, Brooks S, et al. „Shock and Go?” extracorporeal cardio-pulmonary resuscitation in the golden-hour of ROSC. Catheter Cardiovasc Interv. 2016; 88(5): 691-696, doi: 10.1002/ccd.26616, indexed in Pubmed: 27315227.

72. Vase H, Christensen S, Christiansen A, et al. The Impella CP device for acute mechanical circulatory support in refractory cardiac arrest. Resuscitation. 2017; 112: 70-74, doi: 10.1016/j. resuscitation.2016.10.003, indexed in Pubmed: 27751862.

73. Ellert J, Jensen MJ, Jensen LO, et al. Percutaneous biventricular cardiac assist device in cardiogenic shock and refractory cardiac arrest. EuroIntervention. 2018; 13(18): e2114-e2115, doi: 10.4244/EIJ-D-17-00637, indexed in Pubmed: 29039311.

74. Schmidt M, Burrell A, Roberts L, et al. Predicting survival after ECMO for refractory cardiogenic shock: the survival after veno-arterial-ECMO (SAVE)-score. Eur Heart J. 2015; 36(33): 2246-2256, doi: 10.1093/eurheartj/ehv194, indexed in Pubmed: 26033984.

75. Muller G, Flecher E, Lebreton G, et al. The ENCOURAGE mortality risk score and analysis of long-term outcomes after VAECMO for acute myocardial infarction with cardiogenic shock. Intensive Care Med. 2016; 42(3): 370-378, doi: 10.1007/s00134016-4223-9, indexed in Pubmed: 26825953.

76. Peigh G, Cavarocchi N, Keith SW, et al. Simple new risk score model for adult cardiac extracorporeal membrane oxygenation: simple cardiac ECMO score. J Surg Res. 2015; 198(2): 273-279, doi: 10.1016/j.jss.2015.04.044, indexed in Pubmed: 25990694.
77. Glober NK, Tainter CR, Abramson TM, et al. A simple decision rule predicts futile resuscitation of out-of-hospital cardiac arrest. Resuscitation. 2019; 142: 8-13, doi: 10.1016/j.resuscitation.2019.06.011, indexed in Pubmed: 31228547.

78. Guglin M, Zucker MJ, Bazan VM, et al. Venoarterial ECMO for Adults: JACC Scientific Expert Panel. J Am Coll Cardiol. 2019; 73(6): 698-716, doi: 10.1016/j.jacc.2018.11.038, indexed in Pubmed: 30765037.

79. Keebler ME, Haddad EV, Choi CW, et al. Venoarterial extracorporeal membrane oxygenation in cardiogenic shock. JACC Heart Fail. 2018; 6(6): 503-516, doi: 10.1016/j.jchf.2017.11.017, indexed in Pubmed: 29655828.

80. Thiele H, Zeymer U, Neumann FJ, et al. IABP-SHOCK II Trial Investigators. Intraaortic balloon support for myocardial infarction with cardiogenic shock. N Engl J Med. 2012; 367(14): 1287-1296, doi: 10.1056/NEJMoa1208410, indexed in Pubmed: 22920912.

81. Thiele H, Zeymer U, Thelemann N, et al. IABPSHOCK II Trial (Intraaortic Balloon Pump in Cardiogenic Shock II) Investigators. Intra-aortic balloon pump in cardiogenic shock complicating acute myocardial infarction: long-term 6 -year outcome of the randomized IABPSHOCK II trial. Circulation. 2019; 139(3): 395-403, doi: 10.1161/circulationaha.118.038201.

82. Fotopoulos GD, Mason MJ, Walker S, et al. Stabilisation of medically refractory ventricular arrhythmia by intra-aortic balloon counterpulsation. Heart. 1999; 82(1): 96-100, doi: 10.1136/ hrt.82.1.96, indexed in Pubmed: 10377318.

83. Goyal D, Nadar SK, Koganti S, et al. Successful use of intraaortic counter pulsation therapy for intractable ventricular arrhythmia in patient with severe left ventricular dysfunction and normal coronary arteries. Cardiol J. 2010; 17: 401-403, indexed in Pubmed: 20690098.

84. Seyfarth M, Sibbing D, Bauer I, et al. A randomized clinical trial to evaluate the safety and efficacy of a percutaneous left ventricular assist device versus intra-aortic balloon pumping for treatment of cardiogenic shock caused by myocardial infarction. J Am Coll Cardiol. 2008; 52(19): 1584-1588, doi: 10.1016/j. jacc.2008.05.065, indexed in Pubmed: 19007597.

85. Ouweneel DM, Eriksen E, Sjauw KD, et al. Percutaneous Mechanical Circulatory Support Versus Intra-Aortic Balloon Pump in Cardiogenic Shock After Acute Myocardial Infarction. J Am Coll Cardiol. 2017; 69(3): 278-287, doi: 10.1016/j. jacc.2016.10.022, indexed in Pubmed: 27810347.

86. Basir MB, Schreiber TL, Grines CL, et al. Effect of early initiation of mechanical circulatory support on survival in cardiogenic shock. Am J Cardiol. 2017; 119(6): 845-851, doi: 10.1016/j.amjcard.2016.11.037, indexed in Pubmed: 28040188.

87. Basir MB, Schreiber T, Dixon S, et al. Feasibility of early mechanical circulatory support in acute myocardial infarction complicated by cardiogenic shock: The Detroit cardiogenic shock initiative. Catheter Cardiovasc Interv. 2018; 91(3): 454-461, doi: 10.1002/ccd.27427, indexed in Pubmed: 29266676.

88. Thiele H, Jobs A, Ouweneel DM, et al. Percutaneous short-term active mechanical support devices in cardiogenic shock: a systematic review and collaborative meta-analysis of randomized trials. Eur Heart J. 2017; 38(47): 3523-3531, doi: 10.1093/eurheartj/ehx363, indexed in Pubmed: 29020341.

89. Schrage B, Ibrahim K, Loehn T, et al. Impella support for acute myocardial infarction complicated by cardiogenic shock: a matched-pair IABPSHOCK II trial 30-day mortality analysis. Circulation. 2019; 139(10): 1249-1258, doi: 10.1161/circulationaha.118.036614. 
90. Basir MB, Kapur NK, Patel K, et al. National Cardiogenic Shock Initiative Investigators. Improved Outcomes Associated with the use of Shock Protocols: Updates from the National Cardiogenic Shock Initiative. Catheter Cardiovasc Interv. 2019; 93(7): 1173-1183, doi: 10.1002/ccd.28307, indexed in Pubmed: 31025538.

91. Chiu CY, Hättasch R, Praeger D, et al. Percutaneous biventricular Impella support in therapy-refractory cardiogenic shock. Heart Lung. 2018; 47(3): 250-252, doi: 10.1016/j.hrtlng.2018.03.009, indexed in Pubmed: 29628145.

92. Dalal PK, Mertens A, Shah D, et al. Hemodynamic support using percutaneous transfemoral Impella 5.0 and Impella RP for refractory cardiogenic shock. Case Rep Cardiol. 2019; 2019: 4591250, doi: 10.1155/2019/4591250, indexed in Pubmed: 30809398.

93. Sheu JJ, Tsai TH, Lee FY, et al. Early extracorporeal membrane oxygenator-assisted primary percutaneous coronary intervention improved 30-day clinical outcomes in patients with ST-segment elevation myocardial infarction complicated with profound cardiogenic shock. Crit Care Med. 2010; 38(9): 1810-1817, doi: 10.1097/CCM.0b013e3181e8acf7, indexed in Pubmed: 20543669.

94. Chung SY, Tong MS, Sheu JJ, et al. Short-term and long-term prognostic outcomes of patients with ST-segment elevation myocardial infarction complicated by profound cardiogenic shock undergoing early extracorporeal membrane oxygenator-assisted primary percutaneous coronary intervention. Int J Cardiol. 2016; 223: 412-417, doi: 10.1016/j.ijcard.2016.08.068, indexed in Pubmed: 27544596.

95. Cheng R, Hachamovitch R, Kittleson M, et al. Clinical outcomes in fulminant myocarditis requiring extracorporeal membrane oxygenation: a weighted meta-analysis of 170 patients. J Card Fail. 2014; 20(6): 400-406, doi: 10.1016/j.cardfail.2014.03.005, indexed in Pubmed: 24642377.

96. Asaumi Y, Yasuda S, Morii I, et al. Favourable clinical outcome in patients with cardiogenic shock due to fulminant myocarditis supported by percutaneous extracorporeal membrane oxygenation. Eur Heart J. 2005; 26(20): 2185-2192, doi: 10.1093/eurhearti/ehi411, indexed in Pubmed: 16014643.

97. Matsumoto M, Asaumi Y, Nakamura Y, et al. Clinical determinants of successful weaning from extracorporeal membrane oxygenation in patients with fulminant myocarditis. ESC Heart Fail. 2018; 5(4): 675-684, doi: 10.1002/ehf2.12291, indexed in Pubmed: 29757498.

98. Ouweneel DM, Schotborgh JV, Limpens J, et al. Extracorporeal life support during cardiac arrest and cardiogenic shock: a systematic review and meta-analysis. Intensive Care Med. 2016; 42(12): 1922-1934, doi: 10.1007/s00134-016-4536-8, indexed in Pubmed: 27647331.

99. Russo JJ, Aleksova N, Pitcher I, et al. Left ventricular unloading during extracorporeal membrane oxygenation in patients with cardiogenic shock. J Am Coll Cardiol. 2019; 73(6): 654-662, doi: 10.1016/j.jacc.2018.10.085, indexed in Pubmed: 30765031.

100. Aso S, Matsui H, Fushimi K, et al. The effect of intraaortic balloon pumping under venoarterial extracorporeal membrane oxygenation on mortality of cardiogenic patients: an analysis using a nationwide inpatient database. Crit Care Med. 2016; 44(11): 1974-1979, doi: 10.1097/CCM.0000000000001828, indexed in Pubmed: 27322361.

101. Kuchibhotla S, Esposito ML, Breton C, et al. Acute biventricular mechanical circulatory support for cardiogenic shock. J Am Heart Assoc. 2017; 6(10), doi: 10.1161/JAHA.117.006670, indexed in Pubmed: 29054842.

102. Kapur N, Breton C, O'Kelly R, et al. TCT-126 Simultaneous, not Staged, Deployment of Biventricular Micro-Axial Flow Impella Catheters (BiPella) is Associated with Improved Survival for Cardiogenic Shock Involving Biventricular Failure. J Am Coll Cardiol. 2016; 68(18): B51, doi: 10.1016/j.jacc.2016.09.032.

103. Burzotta F, Dudek D. Looking For Vascular Access Standardization In Percutaneous Cardiovascular Procedures. EuroIntervention. 2020: in press.

104. Freund A, Jobs A, Lurz P, et al. Frequency and impact of bleeding on outcome in patients with cardiogenic shock. JACC Cardiovasc Interv. 2020; 13(10): 1182-1193, doi: 10.1016/j.jcin.2020.02.042, indexed in Pubmed: 32438988.

105. Junquera L, Urena M, Latib A, et al. Comparison of transfemoral versus transradial secondary access in transcatheter aortic valve replacement. Circ Cardiovasc Interv. 2020; 13(3): e008609, doi: 10.1161/CIRCINTERVENTIONS.119.008609, indexed in Pubmed: 32089002 . 